\title{
Pengaruh Kreativitas Menggunakan Mind Mapping Berbantu Software Mindomo 3.16 terhadap Hasil Belajar Fisika di SMA pada Materi Momentum dan Impuls
}

\author{
Azizah Ainun Nuha ${ }^{1^{*}}$, Lambang Subagiyo ${ }^{2}$, Zulkarnaen $^{3}$ \\ 1,2,3 Program Studi Pendidikan Fisika Fakultas Keguruan dan IImu Pendidikan \\ Universitas Mulawarman, Samarinda-Indonesia \\ *E-mail : azizahainunnuha13@gmail.com
}

\begin{abstract}
Abstrak
Penelitian ini bertujuan untuk mengetahui pengaruh kreativitas siswa terhadap hasil belajar menggunakan metode Mind Mapping berbantu software Mindomo 3.16. Penelitian dilakukan di SMA Negeri 9 Samarinda kelas X IPA 2 dengan jumlah sampel 27 siswa. Penilaian kreativitas siswa didasarkan pada produk Mind Mapping berbantu software Mindomo 3.16 yang dibuat oleh siswa. Indikator penilaian kreativitas meliputi; menyusun sesuatu yang baru (originality), menurunkan banyak ide (fluency) dan mengubah perspektif (flexibility), link, desain, dan kata kunci. Akumulasi penskoran kreativitas diperoleh persentase tertinggi adalah skor indikator originality sebesar $20 \%$ dan persentase terendah adalah skor indikator desain sebesar $12 \%$. Sedangkan untuk data hasil belajar diperoleh dari tes yang siswa kerjakan. Analisis data yang digunakan adalah uji regresi linier sederhana. Berdasarkan hasil penelitian menunjukkan bahwa terdapat pengaruh sebesar $16 \%$, dapat dikategorikan sebagai korelasi yang rendah sekali. Korelasi ini memenuhi hubungan linier $Y=62,874+0,253 x$.
\end{abstract}

Kata kunci: Kreativitas, Metode Mind Mapping, Hasil Belajar

\begin{abstract}
This research discusses about studying student creativity towards learning outcomes using Mind Mapping method assisted with Mindomo software 3.16. The study was conducted at the 9th grade Natural Sciences Samarinda High School 2 Samarinda with a sample of 27 students. Student creativity assessment is sponsored by Mindomo 3.16 Mind Assisted Software product created by students. Indicator Contains creativity; construct something new (originality), lose many ideas (fluency) and change perspective (flexibility), links, design, and keywords. The accumulation of creativity scoring obtained by the highest percentage is the originality indicator score of $20 \%$ and the lowest percentage is the design indicator score of $12 \%$. While the learning outcomes data obtained from the tests the students will do. Analysis of the data used is a simple linear regression test. Based on the results of research showing as much as $16 \%$, it can be categorized as very low change. This correlation satisfies the linear relationship $Y=62,874+0.253 x$.
\end{abstract}

Keywords: Creativity, Mind Mapping Method, Learning Outcomes

Article History: Received: 2 Desember 2019

Accepted: 30 Desember 2019
Revised : 27 Januari 2020

Published: 31 Januari 2020

How to cite: Nuha, A.A., Subagiyo, L., dan Zulkarnaen. (2020). Pengaruh Kreativitas Menggunakan Mind Mapping Berbantu Software Mindomo 3.16 Terhadap Hasil Belajar Fisika di SMA pada Materi Momentum dan Impuls, 1(1). pp. 27-34. Retrieved from http://jurnal.fkip.unmul.ac.id/index.php/jpfp/index

Copyright (C) Januari 2020, Jurnal Literasi Pendidikan Fisika 


\section{PENDAHULUAN}

IImu pengetahuan dan teknologi abad 21 yang terus berkembang memunculkan tantangan baru dalam dunia pendidikan. Perkembangan pendidikan terus berfokus pada pengembangan keterampilan (skill), kreativitas, keterampilan dalam memecahkan masalah, serta mampu memanfaatkan teknologi dengan baik (Zubaidah, 2016).

Keterampilan, intelektual, sosial dan personal dibangun tidak hanya berlandaskan dengan rasio dan logika saja, tetapi juga inspirasi, kreativitas, moral intuisi (emosi) dan spiritual (Pasaribu \& Pasarini, 2017). Kreativitas diperlukan untuk pembelajaran sains, teknologi dan seni yang mencakup penerapannya pada kehidupan sehari-hari (Runco, 2014).

Proses pembelajaran di sekolah merupakan faktor penting dalam ketercapaian kompetensi global. Guru yang berperan sebagai manajer di dalam kelas berkewajiban untuk merencanakan, mengorganisasi, memandu dan mengevaluasi hasil kegiatan belajar mengajar yang dikelolanya. Hal tersebut dilakukan untuk mencapai tujuan pembelajaran yang ingin dicapai, oleh karenanya guru diharapkan mampu menciptakan suasana yang menyenangkan dan kondusif agar siswa terangsang untuk lebih ingin mengetahui materi, senang menanyakan dan berani mengajukan pendapat serta melakukan percobaan yang menuntut pengalaman baru (Sambada, 2012).

Suasana belajar yang kondusif umumnya masih sulit ditemukan pada pembelajaran fisika di sekolah, dikarenakan sistem pembelajaran yang masih berpusat pada guru dan keterbatasan media pembelajaran fisika di kelas (Nurlaila, 2016). Sehingga, masih banyak siswa yang kurang aktif dan kreatif dalam pembelajaran, hal ini secara otomatis juga mempengaruhi hasil belajar fisika siswa.

Salah satu tujuan pembelajaran fisika yaitu peserta didik diharapkan dapat memahami konsep fisika melalui proses belajar mengajar yang tepat. Sebagai indikator pemahaman konsep fisika siswa, dibutuhkan pola pikir yang menyebar dan visualisasi materi yang mampu memudahkan siswa menghubungkan pengetahuan awal dengan pengetahuan yang baru didapat. Semakin banyak teori yang diperoleh namun tidak dapat siswa pahami dengan baik, maka akses luas ke web pun telah meningkatkan besarnya masalah. Penggunaan media pembelajaran yang dapat membantu ketercapaian indikator pemahaman konsep fisika di atas adalah dengan membuat peta pikiran (mind mapping).

Mind mapping membantu siswa mengatur dan memahami informasi jauh lebih efektif dari pada teknik lainnya, dengan mengurangi masalah yang dibuat oleh informasi yang berlebihan (Guerrero, 2018). Pemberian stimulus berupa elemen visual menjadikan pemetaan yang dibuat mudah dianalisis, dipahami dan dihafal untuk melihat hubungan antara bagian-bagian informasi dari pemecahan masalah teks linear. Rosciano (2015) dalam penelitiannya menuliskan bahwa ketika siswa mengembangkan peta pikiran, mereka menemukan diri mereka mengeksplorasi konsep yang merupakan kunci asosasi terorganisir, berwarna-warni, bersemangat dan logis.

Digital mind mapping adalah file terkompresi tunggal yang dapat digunakan pada perangkat lunak (Guerrero, 2018). Penelitian ini pada prosesnya memanfaatkan software Mindomo 3.16 yang akan menyebabkan proses belajar menjadi menyenangkan dan mendorong siswa untuk aktif, kreatif dan mandiri dalam belajar.

Berdasarkan permasalahan tersebut, maka penelitian ini dilakukan dengan tujuan untuk mengetahui pengaruh kreativitas siswa dengan menggunakan mind mapping berbantu software Mindomo 3.16 terhadap hasil belajar Fisika di SMA.

\section{METODE}

Penelitian ini merupakan penelitian kuantitatif pre-eksperimental dengan tipe desain One Group Pre-test Post-test. Adapun desain penelitian dapat dilihat pada tabel berikut;

Tabel 1. Desain One Group Pre-test Post-test

\begin{tabular}{ccc}
\hline Pre-test & Perlakuan & Post-test \\
\hline$O_{1}$ & $X$ & $O_{2}$ \\
\hline
\end{tabular}

Keterangan:

$O_{1} \quad$ : Nilai Pre-test

$X \quad$ : Perlakuan (treatment) yang diberikan adalah metode Mind Mapping berbantu software Mindomo 3.16

$\mathrm{O}_{1} \quad$ : Nilai Post-test 
Kreativitas Menggunakan Mind...

Data diperoleh dengan menggunakan instrumen tes dan non-tes. Data tes berupa hasil belajar siswa yang diperoleh melalui tes awal (pre-test) dan tes akhir (post-test). Data nontes berupa penilaian kreativitas siswa melalui produk mind map yang dibuat oleh siswa.

Tes disusun berdasarkan pada indikator yang hendak dicapai. Instrument tes mencakup ranah kognitif pada aspek mengingat (C1) sampai analisis (C4). Tes dilakukan dua kali yaitu sebelum perlakuan (pre-test) dan sesudah perlakuan (post-test), dengan soal tes yang berbeda namun sesuai dalam level untuk meminimalisir faktor lain diluar dari perlakuan yang diberikan. Instrumen ini berbentuk esai dan berjumlah 10 soal untuk setiap tes. Sedangkan, indikator penilaian non-tes (produk mind map siswa) yang digunakan dapat dilihat pada tabel 2.

Teknik analisis data yang digunakan adalah uji regresi linier sederhana, uji signifikansi dan uji $\mathrm{N}$-gain. Untuk mengetahui pengaruh kreativitas siswa menggunakan mind mapping terhadap hasil belajar fisika yang diberikan dengan melihat hasil belajar siswa dan untuk mengetahui keberhasilan pre-test dan post-test siswa.

Tabel 2. Rubrik Kriteria Penilaian Kreativitas Siswa dalam Membuat Mind Mapping

\begin{tabular}{|c|c|c|c|}
\hline \multirow{2}{*}{ Penilaian } & \multicolumn{3}{|c|}{ Skor } \\
\hline & 3 & 2 & 1 \\
\hline $\begin{array}{l}\text { Menyusun sesuatu } \\
\text { yang baru (originality) }\end{array}$ & $\begin{array}{l}\text { Menyimpan semua kata } \\
\text { kunci pada cabang yang } \\
\text { berbeda dari kelompok/ } \\
\text { orang lain. }\end{array}$ & $\begin{array}{l}\text { Menyimpan kata kunci } \\
\text { pada cabang yang } \\
\text { berbeda dari kelompok/ } \\
\text { orang lain. }\end{array}$ & $\begin{array}{l}\text { Menyimpan kata kunci } \\
\text { pada cabang yang sama } \\
\text { dengan kelompok / orang } \\
\text { lain. }\end{array}$ \\
\hline $\begin{array}{lr}\text { Menurunkan } & \text { banyak ide } \\
\text { (fluency) r dan } & \text { mengubah } \\
\text { merspektif } \\
\text { dengan } & \text { mudah } \\
\text { (flexibility) } & \end{array}$ & $\begin{array}{l}\text { Siswa memasukkan lebih } \\
\text { dari } 4 \text { konsep ke dalam } \\
\text { mind mapnya dalam } \\
\text { waktu yang ditentukan. }\end{array}$ & $\begin{array}{llr}\text { Siswa memasukkan } 3 \\
\text { sampai } 4 \text { konsep ke } \\
\text { dalam mind mapnya } \\
\text { dalam waktu yang } \\
\text { ditentukan. }\end{array}$ & $\begin{array}{l}\text { Siswa memasukkan } 1 \\
\text { sampai } 2 \text { konsep ke dalam } \\
\text { mind mapnya dalam waktu } \\
\text { yang ditentukan. }\end{array}$ \\
\hline $\begin{array}{l}\text { Mengembangkan ide } \\
\text { lain dari suatu ide } \\
\text { (elaboration) }\end{array}$ & $\begin{array}{l}\text { Siswa membuat lebih dari } \\
15 \text { cabang dalam } 1 \text { mind } \\
\text { map. }\end{array}$ & $\begin{array}{l}\text { Siswa membuat } 10-15 \\
\text { cabang dalam } 1 \text { mind } \\
\text { map. }\end{array}$ & $\begin{array}{l}\text { Siswa membuat kurang dari } \\
10 \text { cabang dalam } 1 \text { mind } \\
\text { map. }\end{array}$ \\
\hline Hubungan (link) & $\begin{array}{l}\text { Siswa menghubung-kan } \\
\text { satu konsep dengan } \\
\text { konsep lainnya dengan } \\
\text { benar. }\end{array}$ & $\begin{array}{l}\text { Siswa menghubung-kan } \\
\text { satu konsep dengan } \\
\text { konsep lainnya namun } \\
\text { tidak tepat. }\end{array}$ & $\begin{array}{l}\text { Siswa tidak menghubung- } \\
\text { kan satu konsep dengan } \\
\text { konsep lainnya. }\end{array}$ \\
\hline $\begin{array}{l}\text { Desain (warna } \\
\text { gambar) }\end{array}$ & $\begin{array}{l}\text { Menggunakan warna } \\
\text { berbeda } \\
\text { disetiap cabang dan } \\
\text { pemberian } \\
\text { gambar/ simbol pada ide } \\
\text { sentral, cabang utama } \\
\text { dan cabang lainnya. }\end{array}$ & $\begin{array}{l}\text { Menggunakan warna } \\
\text { berbeda } \\
\text { disetiap cabang dan } \\
\text { pemberian } \\
\text { gambar/ simbol hanya } \\
\text { pada ide sentral, dan } \\
\text { cabang utama. }\end{array}$ & $\begin{array}{l}\text { Mengggunakan } \\
\text { warna berbeda } \\
\text { disetiap cabang } \\
\text { dan pemberian } \\
\text { gambar/ simbol hanya pada } \\
\text { ide sentral. }\end{array}$ \\
\hline Kata kunci & $\begin{array}{l}\text { Penggunaan kata kunci } \\
\text { yang sangat efektif } \\
\text { (semua ide ditulis dalam } \\
\text { bentuk kata kunci) }\end{array}$ & $\begin{array}{l}\text { Semua ide ditulis dalam } \\
\text { kata kunci dan kalimat }\end{array}$ & $\begin{array}{l}\text { Penggunaan kata kunci } \\
\text { terbatas (semua ide ditulis } \\
\text { dalam bentuk kalimat) }\end{array}$ \\
\hline
\end{tabular}


Kreativitas Menggunakan Mind...

\section{HASIL DAN PEMBAHASAN}

\section{HASIL}

1. Kreatifitas siswa

Penilaian kreativitas siswa didapat dari produk mind mapping yang dibuat oleh siswa menggunakan software Mindomo 3.16.

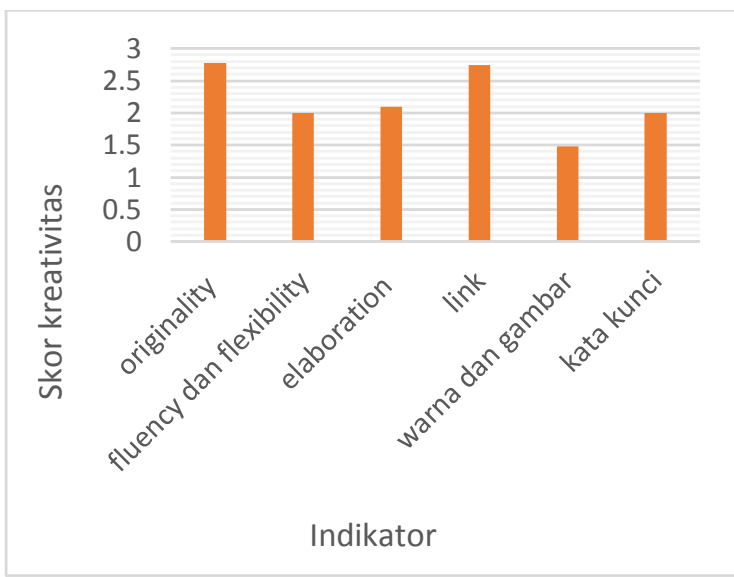

Gambar 1. Grafik Rata-rata Kreativitas setiap Indikator

Berdasarkan analisis kreativitas pada lampiran 12, maka diperoleh persentase skor kreativitas per indikator yaitu, originality, fluency dan flexibility, elaboration, link, warna dan gambar, serta kata kunci berdasarkan kategori 3 (Baik), 2 (Sedang) dan 1 (Kurang) sebagai berikut.

Tabel 3. Persentase Skor Indikator Kreativitas

\begin{tabular}{cccc}
\hline \multirow{2}{*}{ Indikator } & \multicolumn{3}{c}{ Kategori } \\
\cline { 2 - 4 } & $\mathbf{3}$ & $\mathbf{2}$ & $\mathbf{1}$ \\
\hline Originality & $77,78 \%$ & $22,22 \%$ & $0 \%$ \\
\hline $\begin{array}{c}\text { Fluency dan } \\
\text { Flexibility }\end{array}$ & $29,63 \%$ & $40,74 \%$ & $29,63 \%$ \\
\hline Elaboration & $33,33 \%$ & $40,74 \%$ & $25,93 \%$ \\
\hline Link & $74,07 \%$ & $25,93 \%$ & $0 \%$ \\
\hline $\begin{array}{c}\text { Warna dan } \\
\text { gambar }\end{array}$ & $14,81 \%$ & $18,52 \%$ & $66,67 \%$ \\
\hline Kata kunci & $25,93 \%$ & $48,15 \%$ & $25,93 \%$ \\
\hline \multicolumn{4}{c}{ (Sumber: Hasil Penelitian, 2018) }
\end{tabular}

2. Hasil Belajar Siswa

Data hasil belajar siswa diperoleh dari hasil skor post-test yang dikerjakan oleh kelas X IPA 2.
Tabel 4. Persentase Ketuntasan Belajar Siswa dalam mencapai KKM

\begin{tabular}{cccc}
\hline $\begin{array}{c}\text { Interval } \\
\text { Nilai }\end{array}$ & Ket & $\begin{array}{c}\text { Jml } \\
\text { Siswa }\end{array}$ & Persentase \\
\hline $0 \geq X>75$ & $\begin{array}{c}\text { Belum } \\
\text { Tuntas }\end{array}$ & 3 & $11,11 \%$ \\
\hline $75 \leq X \leq 100$ & Tuntas & 24 & $88,89 \%$ \\
\hline
\end{tabular}

Tabel 5. Persentase Kategori Skor Hasil Belajar

\begin{tabular}{cccc}
\hline Rentang Nilai & Kategori & $\begin{array}{c}\text { Jml } \\
\text { Siswa }\end{array}$ & Persentase \\
\hline $80 \leq X \leq 100$ & $\begin{array}{c}\text { Baik } \\
\text { sekali }\end{array}$ & 16 & $59,26 \%$ \\
\hline $70 \leq X \leq 80$ & Baik & 10 & $37,04 \%$ \\
\hline $60 \leq X \leq 70$ & $\begin{array}{c}\text { Cukup } \\
\text { baik }\end{array}$ & 0 & $0,00 \%$ \\
\hline $50 \leq X \leq 60$ & Kurang & 1 & $3,70 \%$ \\
\hline $0 \leq X \leq 50$ & $\begin{array}{c}\text { Kurang } \\
\text { sekali }\end{array}$ & 0 & $0,00 \%$ \\
\hline \multicolumn{4}{c}{ Sumber: Hasil Penelitian, 2018) }
\end{tabular}

Analisis keberhasilan pre-test dan post-test diidentifikasikan menggunakan $\mathrm{N}$-gain.

Tabel 6. Persentase Kategori Skor Keberhasilan Pre-test dan Post-test Siswa

\begin{tabular}{cccc}
\hline Nilai $\boldsymbol{N}$-gain & Kategori & $\begin{array}{c}\text { Jmlh } \\
\text { Siswa }\end{array}$ & Persentase \\
\hline $\mathrm{g}>0,7$ & Tinggi & 22 & $81,48 \%$ \\
\hline $0,3 \leq \mathrm{g} \leq 0,7$ & Sedang & 5 & $18,52 \%$ \\
\hline $\mathrm{g}<0,3$ & Rendah & 0 & $0,00 \%$ \\
\hline & (Sumber: Hasil Penelitian, 2018)
\end{tabular}

3. Pengaruh Kreativitas terhadap Hasil Belajar Fisika Siswa

Berdasarkan data yang terdapat pada lampiran 14 didapatkan hasil regresi linear sederhana yang tersaji dalam tabel sebagai berikut.

Table 7. Analisis Regresi Linier Sederhana Kreativitas dengan Metode Mind Mapping berbantu Software Mindomo 3.16 Terhadap Hasil Belajar Siswa

\begin{tabular}{cccc}
\hline $\begin{array}{c}\text { Koefisien } \\
\begin{array}{c}\text { Penduga } \\
\text { (a) }\end{array}\end{array}$ & $\begin{array}{c}\text { Koefisien } \\
\text { Intersap } \\
\text { (b) }\end{array}$ & $\begin{array}{c}\text { Koefisien } \\
\text { Korelasi } \\
(\mathbf{r})\end{array}$ & $\begin{array}{c}\text { Koefisien } \\
\text { Determinasi } \\
\text { (D) }\end{array}$ \\
\hline 62,874 & 0,253 & 0,399 & $16 \%$ \\
\hline \multicolumn{4}{c}{ (Sumber: Hasil Penelitian, 2018) }
\end{tabular}

Keterangan:

Nilai $r>0$, ada pengaruh antara metode mind 
mapping terhadap hasil belajar siswa.

Berikut merupakan tabel analisis dara uji signifikansi dengan menggunakan SPSS 20.

Tabel 8. Analisis Data Uji Signifikansi

\begin{tabular}{ccccc}
\hline $\begin{array}{c}\text { Sumber } \\
\text { Variasi }\end{array}$ & JK & Db & RK & FHitung \\
\hline Regresi & 208,487 & 1 & 208,487 & 4,746 \\
\hline Residu & 1098,179 & 25 & 43,927 \\
\hline Total & 1306,667 & 26 \\
\hline \multicolumn{5}{c}{ (Sumber: Hasil Penelitian, 2018) }
\end{tabular}

\section{PEMBAHASAN}

Penelitian ini bertujuan untuk mengetahui pengaruh kreativitas menggunakan metode mind mapping berbantu software Mindomo 3.16 terhadap hasil belajar siswa kelas X IPA 2 di SMA Negeri 9 Samarinda pada materi momentum dan impuls, tahun ajaran 2017/ 2018. Pada penelitian ini digunakan kelas $X$ IPA 2 sebagai sampel penelitian dengan jumlah siswa yaitu 27 siswa, dengan pertimbangan kemampuan siswa yang terdistribusi merata dari yang tinggi, sedang maupun rendah. Hal ini sesuai dengan perencanaan awal yaitu menggunakan teknik pengambilan sampel berupa Nonprobability Sampling dengan tipe Purposive Sampling. Berdasarkan hasil penelitian yang telah dilaksanakan, didapat data yang akan dibahas sebagai berikut.

Analisis data kreativitas sebagai variabel bebas pada penelitian ini didapat dari penilaian produk mind mapping yang dibuat oleh siswa. Proses belajar mengajar yang menggunakan kreativitas dengan metode mind mapping memiliki 4 indikator dasar yaitu, kemampuan dalam melahirkan banyak ide dan gagasan (fluency), kemampuan untuk menggunakan bermacam-macam pendekatan untuk memecahkan persoalan (flexibility), kemampuan untuk menyusun sesuatu yang baru (originality), dan kemampuan untuk mengembangkan suatu ide dari ide yang lain (elaboration). Selain itu, ada tiga indikator lain yang juga berpengaruh yaitu, kemampuan menghubungkan antar konsep dengan benar, kemampuan menggunakan warna, gambar/ ilustrasi untuk mendeskripsikan suatu konsep serta kemampuan menggunakan kata kunci yang sangat efektif dalam menuliskan ide maupun gagasan. Skor yang digunakan untuk masing-masing indikator adalah 1,2 atau 3, yang mengindikasikan jika semakin tinggi skor yang diperoleh maka semakin baik pula kemampuan kreativitas siswa untuk masingmasing indikator.

Berdasarkan tabel 3, diperoleh data indikator kreativitas originality kategori baik (3) sebesar $77,78 \%$ dengan siswa sebanyak 21 siswa dan 6 siswa lainnya termasuk dalam kategori sedang (2) sebesar 22,22\%. Data indikator kreativitas fluency dan flexibility kategori baik (3) sebesar 29,63\% dengan siswa sebanyak 8 siswa, kategori sedang (2) sebesar $40,74 \%$ oleh 11 siswa dan 8 siswa lainnya termasuk dalam kategori kurang (1) sebesar $29,63 \%$. Data indikator kreativitas elaboration kategori baik (3) sebesar 33,33\% dengan siswa sebanyak 9 siswa, kategori sedang (2) sebesar $40,74 \%$ oleh 11 siswa dan 7 siswa lainnya termasuk dalam kategori kurang (1) sebesar $25,93 \%$. Data indikator kreativitas link kategori baik (3) sebesar $74,07 \%$ dengan siswa sebanyak 20 siswa dan 7 siswa lainnya termasuk dalam kategori sedang (2) sebesar $25,93 \%$. Data indikator kreativitas warna dan gambar kategori baik (3) sebesar 14.81\% dengan siswa sebanyak 4 siswa, kategori sedang (2) sebesar $18,52 \%$ oleh 5 siswa dan 18 siswa lainnya termasuk dalam kategori kurang (1) sebesar $66,67 \%$. Data indikator kreativitas kata kunci kategori baik (3) sebesar $25,93 \%$ dengan siswa sebanyak 7 siswa, kategori sedang (2) sebesar $48,15 \%$ oleh 13 siswa dan 7 siswa lainnya termasuk dalam kategori kurang (1) sebesar 25,93\%.

Berdasarkan penelitian, siswa kelas X IPA 2 dapat dikatakan kreatif dikarenakan lebih dari $50 \%$ persentase kategori penilaian kreativitas siswa berada pada kategori baik sekali/ kreatif sekali dan baik/ kreatif. Berdasarkan Gambar 1, kemampuan siswa untuk menyusun sesuatu yang baru dan kemampuan dalam membuat hubungan antar konsep dengan benar cenderung baik dengan rata-rata sebesar 2,78 dan 2,74 (hampir mendekati angka 3). Kemampuan siswa dalam melahirkan banyak ide/ gagasan dan mengubah perspektif dengan mudah dalam menyelesaikan masalah cenderung sedang dengan rata-rata sebesar 2 . Kemampuan siswa dalam mengembangkan 
suatu ide dari ide lain cenderung sedang dengan rata-rata sebesar 2,1. Hal ini tidak jauh berbeda dengan kemampuan siswa menggunakan kata kunci yang efektif dalam menuliskan ide maupun gagasan juga cenderung sedang dengan rata-rata sebesar 2 . Sedangkan, kemampuan siswa dalam menggunakan warna, gambar/ ilustrasi untuk mendeskripsikan suatu konsep cenderung kurang dengan rata-rata sebesar 1,48 hal ini dikarenakan beberapa mind map yang siswa buat menggunakan template yang sudah ada dan tidak adanya ilustrasi yang menggambarkan konsep tertentu.

Analisis data hasil belajar sebagai variabel terikat diperoleh dari nilai ketuntasan belajar siswa (post-test) setelah perlakuan berupa metode pembelajaran mind mapping diberikan. Berdasarkan data penelitian yang diperoleh, dapat diinterpretasikan bahwa rata-rata hasil belajar siswa telah mencapai KKM fisika yaitu 75 dengan persentase ketuntasan mencapai $88,89 \%$. Hasil belajar siswa dapat dikatakan baik, karena kecenderungan penilaian hasil belajar siswa berada pada kategori baik sekali dan baik. Setelah penilaian hasil belajar siswa (post-test), selanjutnya dianalisis keberhasilan pre-test (tes sebelum perlakuan diberikan) dan post-test yang diidentifikasi menggunakan peningkatan nilai $\mathrm{N}(\mathrm{N}$-gain). Berdasarkan tabel 6 tidak terdapat siswa dengan nilai $\mathrm{N}$-gain dalam kategori rendah. Nilai $\mathrm{N}$-gain siswa kelas X IPA 2 berada pada kategori sedang dan tinggi, 5 siswa dalam kategori sedang dengan persentase $18,52 \%$ dan 22 siswa lainnya dalam kategori tinggi dengan persentase $81,48 \%$.

Analisis pengaruh kreativitas terhadap hasil belajar fisika siswa pada Tabel 6 menyatakan bahwa nilai hasil belajar bertambah sebesar 0,253 untuk setiap penambahan 1 nilai kreativitas. Korelasi yang terbentuk adalah linier sempurna dengan persentase pengaruh yang diberikan oleh variabel independen kepada variabel dependen sebesar $16 \%$, dapat dikategorikan sebagai korelasi yang rendah sekali. Berdasarkan data pada lampiran 14, dari perhitungan diketahui nilai $F_{\text {tabel }}$ sebesar

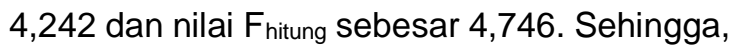
$F_{\text {hitung }}>\mathrm{F}_{\text {tabel }}$ dengan penjelasan bahwa $\mathrm{H}_{0}$ ditolak dan $\mathrm{H}_{1}$ diterima, artinya signifikan.

Berdasarkan interpretasi tabel dan gambar tersebut maka dapat diperoleh pernyataan bahwa $\mathrm{H}_{0}$ ditolak dan $\mathrm{H}_{\mathrm{a}}$ diterima yaitu terdapat pengaruh linier kreativitas terhadap hasil belajar siswa menggunakan metode mind mapping berbantu software Mindomo 3.16 pada kelas X IPA 2 di SMA Negeri 9 Samarinda (materi: impuls dan momentum). Adanya peningkatan ketuntasan hasil belajar siswa merupakan dampak dari regresi yang terjadi.

Pengaruh yang diberikan tidak luput dari proses belajar mengajar yang terlaksana. Penelitian dilakukan sebanyak 4 kali pertemuan, dimana proses pembelajaran dilaksanakan sebanyak 2 kali. Pada pertemuan pertama, siswa diberikan pre-test dengan durasi waktu selama 2 jam pelajaran (90 menit), dilanjutkan dengan pengenalan metode belajar menggunakan mind mapping dan pengoperasian software Mindomo 3.16. Pada pertemuan kedua dan ketiga, dilakukan proses belajar mengajar materi momentum dan impuls dengan metode pembelajaran mind mapping. Pembelajaran tersebut disertai dengan sesi diskusi (brainstorming) dan pembuatan produk mind mapping berbantu software Mindomo 3.16. Pada pertemuan terakhir (keempat), siswa diberikan post-test dengan durasi waktu selama 2 jam (90 menit).

Setiap pertemuan pembelajaran yang dilakukan memiliki alokasi waktu selama 3 jam pelajaran ( $3 \times 45$ menit) dimana sesuai jadwal terlaksana 1 kali tatap muka tiap seminggu, yaitu pada hari Kamis jam 11.45-12.00 WITA kemudian dilanjut jam 12.30-14.00 WITA. Jadi jumlah waktu pembelajaran yang diberikan terhadap siswa adalah 12 jam pelajaran, dengan rincian yaitu 6 jam pelajaran untuk proses belajar mengajar, 2 jam pelajaran untuk pre-test, 2 jam pelajaran untuk pengenalan metode pembelajaran mind mapping serta media pembelajaran yang digunakan yaitu software Mindomo 3.16 dan 2 jam pelajaran untuk post-test.

Pada proses pembelajaran yang terlaksana 2 kali pertemuan, di setiap pertemuan siswa diberikan kesempatan untuk membuat mind map dengan bantuan software Mindomo 3.16 secara individu melalui brainstrming yang dilakukan secara berkelmpok. Brainstorming yang dilakukan mencakup empat peraturan dasar yaitu, tidak menghakimi ide/ gagasan siswa lain, ada notulen yang mencatat ide/ gagasan siswa, adanya fasilitator untuk 
Kreativitas Menggunakan Mind...

membangun ide dan mengeluarkan pemikiran baru. Penulis tidak membatasi literatur yang siswa gunakan dalam membuat mind map, karena literatur bisa didapatkan dari berbagai sumber bisa dari penjelasan guru ketika menyampaikan materi atau membaca literatur lain, semakin banyak siswa membaca literatur maka semakin siswa dapat mengelaborasi konsep dengan baik. Beberapa produk kreativitas siswa menggunakan metode mind mapping terdapat pada lampiran 13. Penerapan metode pembelajaran mind mapping tidak bisa berdiri sendiri, sehingga sering dikaitkan dengan model atau pendekatan lainnya yang mendukung. Penelitian ini menggunakan model problem based learning oleh Kemendikbud (2016) dengan langkah-langkah pembelajaran sebagai berikut; klarifikasi permasalahan, brainstorming, pengumpulan informasi dan data, berbagi informasi dan berdiskusi untuk menemukan solusi penyelesaian masalah, presentasi hasil penyelesaian masalah, dan refleksi.

Berdasarkan data-data yang diperoleh, hasil penelitian ini sesuai dengan penelitian sebelumnya yang juga menyatakan bahwa kreativitas dengan metode mind mapping memberikan pengaruh terhadap hasil belajar. Penelitian yang dilakukan oleh Anna Buran dan Andrey Filyukov (2015) mengenai teknik mind mapping dalam pembelajaran bahasa. Penelitian yang dilakukan Ibrahim. M. A. Jbeili (2013) mengenai dampak digital mind mapping pada prestasi sains siswa kelas VI di Arab Saudi. Penelitian yang dilakukan Ryani Fauziah dan Fathiah Atalas (2016) mengenai pengaruh penggunaan Lembar Kerja Siswa (LKS) berbasis mind map terhadap hasil belajar siswa SMA pada konsep fluida statis. Penelitian yang dilakukan Annemarie Rosciano (2015) tentang efektivitas mind mapping sebagai strategi pembelajaran aktif pada mahasiswa keperawatan. Penelitian yang dilakukan oleh Purwati, Santosa, \& Rinato (2016), mengenai penerapan model pembelajaran inkuiri dipadu dengan mind mapping untuk meningkatkan kemampuan kognitif siswa. Perbedaan penelitian ini dengan penelitian-penelitian sebelumnya terdapat pada penggunaan media ajar, model pembelajaran dan subjek penelitiannya.

\section{PENUTUP}

Berdasarkan hasil penelitian dan pembahasan yang telah dilakukan maka diperoleh kesimpulan bahwa terdapat pengaruh yang tidak signifikan pada metode mind mapping berbantu software Mindomo 3.16 sebagai pengaplikasian dari kreativitas siswa tehadap hasil belajar siswa kelas X IPA SMA Negeri 9 Samarinda tahun ajaran 2017/ 2018 pada materi momentum dan impuls. Kreativitas siswa kelas X IPA 2 dalam membuat produk mind mapping pada pembelajaran fisika termasuk dalam kategori kreatif, hal ini diikuti dengan ketuntasan hasil belajar siswa yang baik. $\mathrm{N}$-gain rata-rata peningkatan hasil belajar siswa kelas X IPA 2 termasuk dalam kategori tinggi.

Berdasarkan hasil penelitian dan kesimpulan diatas, maka penulis dapat mengemukakan beberapa saran. Bagi peserta didik, agar terus berlatih dalam menganalisis penerapan teori serta konsep fisika pada fenomena alam maupun peristiwa yang sering terjadi sehari-hari, untuk meningkatkan kemampuan pemahaman dan kreativitas agar diperoleh hasil belajar yang lebih baik. Bagi guru, agar dapat menjadikan metode pembelajaran mind mapping digital sebagai salah satu alternatif metode pembelajaran fisika di sekolah, yang memanfaatkan media digital berupa software Mindomo 3.16 agar tercipta suasana belajar mengajar yang aktif dan menyenangkan, sehingga dapat memotivasi siswa untuk semangat belajar dan dapat mengembangkan kreativitas siswa. Bagi sekolah, agar dapat meningkatkan fasilitas untuk pembelajaran kreatif seperti sarana dan prasarana yang mendukung kreativitas berupa media maupun literatur kreativitas agar proses belajar mengajar di kelas bisa menjadi lebih baik dan optimal. Bagi peneliti berikutnya, diharapkan dapat mengembangkan metode pembelajaran mind mapping ini pada beberapa materi fisika lainnya atau dapat mengkolaborasikannya dengan model/ metode/ media pembelajaran lain yang dapat menunjang hasil belajar yang lebih baik. 
Kreativitas Menggunakan Mind...

\section{DAFTAR PUSTAKA}

Buran, A., \& Filyukov, A. (2015). Mind Mapping Technique in Language Learning. Procedia: Social and Behavioral Sciences, 206, 215-218.

Fauziah, R., \& Alatas, F. (2016). Pengaruh Lembar Kerja Siswa Berbasis Mind Map Terhadap Hasil Belajar Siswa SMA Pada Konsep Fluida Statis. Edusains, 8(1),1-8.

Guerrero, J.M. (2018). Data Visualization of Complex Information Through Mind Mapping in Spain and the European Union. Federal Data Science, 103-138.

Jbeili, I.M.A. (2013). The Impact of Digital Mind Maps on Science Achievement among Sixth Grade in Saudi Arabia. ProcediaSocial and Behavioral Sciences, 103, 1078-1087.

Kementrian Pendidikan dan Kebudayaan Direktorat Jendral Pendidikan Dasar dan Menengah. (2016). Modul Pembelajaran untuk Sekolah Menengah Pertama. Jakarta: kemendibud

Nurlaila, L. (2016). Menilai Mind Map Siswa dengan Teknologi Digital. Prosiding Seminar Nasional II Tahun 2016.

Pasaribu, A. \& Saparini. (2017). Pengembangan Instrumen Autentik Assesmen berupa Penilaian Proyek dengan Produk Mind Mapping pada Materi Gaya dan Hukum Newton tentang Gerak. Jurnal Inovasi dan Pembelajaran Fisika, 3 (2), 1-6.

Purwati, W., Santosa, S. dan Rinato, Y. (2016). Penerapan Model Pembelajaran Inkuiri dipadu dengan Mind Mapping untuk Meningkatkan Kemampuan Kognitif Siswa Kelas XI MIPA 2 SMA N 6 Surakarta Semester 2. Bio-Pedagogi, 5(1), 15-19.

Rosciano, A. (2015). The effectiveness of mind mapping as an active learning strategy among associate degree nursing students. Teaching and Learning in Nursing, 10(2) 93-99.

Halliday, D., Resnick, R., \& Walker, J. (2013). Fundamentals of physics. John Wiley \& Sons.

Runco, M. A. (2014). Creativity (2nd ed.). Boston, MA: Academic Press.
Sambada, D. (2012). Peran Kreativitas Siswa terhadap Kemampuan Memecahkan Masalah Fisika dalam Pembelajaran Kontekstual. Jurnal Penelitian Fisika dan Aplikasinya, 2(2), 37-47.

Zubaidah, S. (2016). Keterampilan Abad Ke21: Keterampilan yang Diajarkan melalui Pembelajaran. Seminar Nasional Pendidikan dengan tema Isu-isu Strategis Pembelajaran MIPA Abad 21. 